\title{
Fibromyalgi: Symptomer kan lindres med fysisk aktivitet og kognitiv terapi
}

Det er mye informasjon om fibromyalgi på internett, men ikke alt er godt dokumentert. Denne artikkelen beskriver forskning som finnes om effekten av ikke-medikamentell symptomlindring.

Ranja B. Mindeberg

Bachelorstudent

Høyskolen Kristiania

Muskel- og skjelettsystem Smerte Stress

Sykepleien 2020108 (80924) (e-80924)

DOI: 10.4220/Sykepleiens.2020.80924

\section{Hovedbudskap}

Med utgangspunkt i dagens kunnskap vil et helhetlig behandlingstilbud med opplæring i egen sykdom, fysisk aktivitet og kognitiv terapi være det beste for pasienter med fibromyalgi. Det er gjort altfor lite forskning på ikke-medikamentelle tiltak med tanke på alle som rammes, og de alvorlige konsekvensene som følger med, både for pasientene og samfunnet. Det skyldes trolig sykdommens lave prestisje. 
Fibromyalgi er en av de vanligste smertetilstandene i muskler og ledd, særlig blant kvinner. Sykdommen er en kronisk smertetilstand som påvirker bindevev, muskler, leddbånd og sener. Fibromyalgi er vanskelig å diagnostisere, utfordrende å leve med og krevende å behandle.

For mange av pasientene får lidelsen alvorlige konsekvenser (2). Det tar tid å stille diagnosen, og sykdommen gir mange plager. Mange pasienter blir sykmeldt, ofte i lang tid, og det kan lede til uførhet. I tillegg opplever pasientene ofte å bli mistrodd - fibromyalgi er en lavstatussykdom (3).

\section{Mange pasienter faller utenfor arbeidslivet}

I Folkehelserapporten 2018 kommer det frem at fibromyalgi har en forekomst på omtrent 5 prosent (4). Det betyr at 5 av 100 i den vanlige befolkningen oppfyller kriteriene for sykdommen på et gitt tidspunkt (prevalens).

En norsk doktoravhandling har sett på hvor mange kvinner som får sykdommen over et visst tidsrom (insidens), og har anslått at det gjelder cirka 60 av 10000 kvinner per år (2). Tall fra utlandet varierer noe og ligger både litt over og litt under det som er funnet i Norge.

Fibromyalgi forekommer i alle lag av befolkningen og i alle etniske grupper. Problemene starter normalt mellom 20- og 6o-årsalderen, men også barn får påvist diagnosen. Tidligere har det vært antatt at fibromyalgi først og fremst rammer kvinner, men etter en endring i diagnosekriteriene er det nå en jevnere forekomst mellom kvinner og menn.

\section{$\equiv$ «Legene rangerer fibromyalgi nederst i det medisinske statushierarkiet.»}

Fibromyalgi er en stor utfordring både sosialt, medisinsk og $\varnothing$ konomisk. Tall fra Statistisk sentralbyrå (SSB) viser at 55500 kvinner og 17800 menn kontaktet fastlegen sin for behandling av fibromyalgi i 2015 (5).

Med sykdommen følger ofte stor funksjonshemning - på linje med leddgiktpasienter og med like stor reduksjon i livskvalitet (6). Antall pasienter som faller utenfor arbeidslivet, varierer fra land til land, men tallene i Norge er høye. Fibromyalgi er en vanlig diagnose blant nye uføretrygdede på tross av at den samme diagnosegruppen også topper trygdens avslagsstatistikk. 
Legene rangerer fibromyalgi nederst i det medisinske statushierarkiet. Pasienter føler seg ofte mistrodd og lite respektert blant annet fordi de har en sykdom som ikke synes på utsiden eller avsløres av tester. De blir ofte tilbudt ulike behandlingstilbud med liten eller ingen nytteverdi.

\section{Systematiske oversikter gir et godt overblikk}

Denne artikkelen beskriver en litteraturoversikt som inkluderer systematiske oversikter. Det er en nyttig fremgangsmåte for å få overblikk over et bestemt felt og passer godt med det en pasient eller behandler trenger å vite om mulighetene som foreligger.

Det er laget metoder for fremstilling av pålitelige kunnskapsoversikter, og det finnes også metodekrav for slike «oversikter over oversikter» (7). Ved å se på enkeltstudier for denne tematikken kan det være lett å plukke ut noen med gode resultater og overse andre som ikke er like oppløftende. Systematiske oversikter vil være bedre for å vurdere hele kunnskapsgrunnlaget.

Jeg har bygget videre på et stort arbeid som andre har gjort når de har lett etter, kvalitetskontrollert og oppsummert det som i prinsippet er «all verdens kunnskap» om de ulike tiltakene. Noen av oversiktene er fra noen år tilbake, og det kan hende at det finnes nyere enkeltstudier.

\section{$\equiv \ll$ Det er skuffende at mye forskning ikke er god nok.»}

Kvaliteten på studiene som ble inkludert i oversiktene, viste seg å være gjennomgående lav, noe som gjør at funnene er usikre. Det er skuffende at mye forskning ikke er god nok.

En fordel med systematiske oversikter er at man slår sammen mange studier og derfor får med flere pasienter. Likevel var det for få pasienter i flere av oversiktene, og da blir det vanskelig å trekke sikre konklusjoner.

Jeg søkte i Cochrane Library med ordene «fibromyalgia treatment» i databasen som heter Cochrane Database of Systematic Reviews. Det ga 46 treff. Det var lett å sortere bort oversiktene som handlet om legemidler, og de som ikke handlet spesielt om fibromyalgi. 
Hver av gruppene i Cochrane-samarbeidet har egne søkestrategier og eksperter på søk. Jeg har derfor gått ut fra at alle har gjort en god nok jobb, og har ikke kritisk vurdert søket som ble gjort i hver av oversiktene. Jeg stoler også på kvalitetsvurderingen som ble gjort av hver enkelt studie da oversikten ble laget.

Cochrane-samarbeidet bruker gode metoder (16). De vurderer særlig om det er systematiske forskjeller mellom gruppene i hver studie, såkalt bias. Slike skjevheter vil gjøre tolkningen av funnene vanskelig.

\section{Funn i oversiktene}

\section{Styrketrening}

Styrketrening i 16-21 uker kan vise forbedringer på symptomer som smerte, ømme punkter og livskvalitet (8). Evnen til å gjennomføre normale aktiviteter $\varnothing \mathrm{kte}$, og det samme gjaldt muskelstyrken.

Oversikten viser også at tolv uker med styrketrening med lav intensitet gir bedre resultater enn fleksibilitetstrening. Men med et så lavt antall deltakere som var med i disse studiene, er resultatene usikre. Det er mulig at ny forskning vil vise andre resultater.

\section{Bassengtrening}

I studiene som sammenliknet bassengtrening med trening på land, var det små forskjeller på symptomer som smerte, stivhet og fysisk funksjon (9). De som trente på land, viste en liten $\varnothing$ kning i styrke.

To studier sammenliknet ulike typer bassengtrening med thai chi og stretching, og de sammenliknet bassengtrening i basseng og i sjøvann. Den eneste forskjellen de fant, var på symptomer som stivhet, der thai chi i basseng ga best resultater.

Siden effektene ikke er så store og tiltakene ikke er prøvd på mange mennesker, er det usikkert hvorvidt resultatene er til å stole på. Ny forskning kan påvirke resultatet.

\section{Aerob trening}


Resultatene fra 13 studier viser at aerob trening kan ha en positiv innvirkning på livskvalitet, smerte, stivhet og fysisk funksjon, men ikke nødvendigvis på fatigue (10). Kvaliteten på studiene ble vurdert som lav til moderat, da det burde ha vært flere deltakere i hver studie, og det var en viss usikkerhet om studiedesign for enkelte studier.

Det finnes ikke mye informasjon om bivirkninger forbundet med aerob trening. Noen rapporter beskrev $\varnothing \mathrm{kt}$ smerte eller tretthet hos noen deltakere, og én av de 496 deltakerne som utførte slik trening, opplevde et brudd i foten. Det kan være en tilfeldighet.

\section{Akupunktur}

Akupunktur kan dempe smerter og redusere stivhet, men effekten synes bare å komme etter bruk av elektroakupunktur, ikke ved manuell akupunktur (11). Noen litt usikre data viste at akupunktur kan gi gode resultater sammen med medikamenter og fysisk aktivitet. Effekten varte opp til én måned, men ble ikke vedlikeholdt etter seksmånederskontroll.

Akupunktur er trygt, men ikke nødvendigvis effektivt. Det er $\varnothing$ nskelig med større studier for å kunne fastslå med større sikkerhet hva effekten er av akupunktur som tiltak for denne pasientgruppen.

\section{Kognitiv terapi}

Kognitiv terapi kan gi en liten reduksjon i smertenivå etter tolv ukers behandling (12). Slik terapi ser også ut til å kunne ha en viss effekt på symptomer på depresjon etter tolv uker. Noen studier har målt effektene etter seks måneder, og de ser ut til å holde seg.

Studiene som inngår i oversikten, har vekslende kvalitet, men nærmere analyser (såkalte sensitivitetsanalyser) viste at funnene var ganske robuste.

\section{Helkroppsvibrasjon}

En annen oversikt vurderte effekten av helkroppsvibrasjon (13). Forfatterne inkluderte randomiserte kontrollerte studier av voksne som hadde fibromyalgi. Personer som fikk helkroppsvibrasjon, ble enten sammenliknet med en gruppe som ikke fikk noe annet tilbud, eller med andre som fikk for eksempel fysioterapi. 
Forfatterne vurderte resultater som helserelatert livskvalitet, smerteintensitet, stivhet, fatigue og fysisk funksjon. De fant fire ulike studier med i alt 150 middelaldrende kvinner fra Spania.

Forfatterne registrerte en viss positiv effekt blant annet på spørreskjema - som måler flere konsekvenser av fibromyalgi og livskvalitet, men usikkerheten er stor fordi det var så få pasienter med. Smerteintensitet, stivhet og fatigue ble ikke målt.

\section{Transkutan nervestimulering (TENS)}

TENS er mye brukt, men resultatene fra oversikten som handlet om dette, viser at kvaliteten på studiene var svært lav, hovedsakelig på grunn av mangel på data (14). Derfor har forskerne liten tillit til funnene. Det var ikke nok grunnlag til å konkludere med at TENS er en effektiv type behandling.

\section{Behandlinger for både kropp og sinn}

Ulike behandlinger som benytter både kropp og sinn som «inngang», viste en viss positiv effekt på fysisk funksjon, smerte og stemningsleie for voksne med fibromyalgi (15). Det var mange studier som omhandlet dette.

Ytterligere forskning på utfallet av terapi er imidlertid nødvendig for å fastslå om de positive effektene opprettholdes over tid. Effektene av biofeedback, mindfulness, bevegelsesterapi og avslapningsstrategier er nokså uklare, da studiene var få og resultatene veldig usikre.

\section{Tverrfaglig rehabilitering}

Alle studiene som vurderte effekten av tverrfaglig rehabilitering, hadde lav kvalitet (16). Ingen av de fire enkeltstudiene av fibromyalgi viste effekt. Oversikten er fra 1999, og det er rart at den ikke er oppdatert.

\section{Inaktivitet forverrer stivhet og smerter}

På tross av mange svakheter var det noen funn som kan være av betydning for pasienter med fibromyalgi. Oversikten over aerob trening viste at denne type trening hadde gode resultater for smerte, stivhet og fysisk funksjon, men ikke nødvendigvis for utmattelse. Det står mye om aerob trening i ulike omtaler og anbefalinger til fibromyalgipasienter. 
Siden andre fordeler med slik trening er lavere blodtrykk, sterkere hjerte og hjelp til å kontrollere blodsukker og overvekt, vil det være god trening for alle mennesker. Også pasienter med fibromyalgi vil få positive effekter på den generelle helsen.

Aerob trening trenger ikke å være løping, som vil være altfor utfordrende for mange av disse pasientene. Mange som sliter med mye smerter, kan ofte bli fristet av tanken på å «hvile seg» bedre, eller de kan gi opp av frustrasjon, trekke seg unna og havne i sofakroken.

Ofte vil inaktivitet forverre både stivhet og smerter, og naturligvis vil det ikke være gunstig for kondisjonen. Men gåturer og vanlig dagligdags bevegelse som holder kroppen $\mathrm{i}$ gang, rolige sykkelturer, en tur i skogen og liknende er gode tiltak for kroppen.

\section{Sterkere muskulatur gjør hverdagen enklere}

Oversikten som omhandler styrketrening, viser til gode resultater for fibromyalgipasienter. Ved styrketrening blir man naturligvis sterkere, og dermed kan ulike hverdagsaktiviteter bli enklere å gjennomføre.

Er man svak i muskulaturen og i tillegg har vondt, kan små dagligdagse gjøremål være smertefulle. Sterkere muskulatur kan gjøre hverdagen enklere, og det er lettere å bevege seg i en vond kropp når en sterk muskulatur hjelper å holde den oppe.

Bassengtrening ga ingen viktige resultater i den aktuelle oversikten, og det er behov for mer forskning på området. Likevel er det mange behandlingssteder som bruker bassengtrening for fibromyalgipasienter, helst i oppvarmet basseng, gjerne 34 grader.

Tiltak som benytter både kropp og sinn som «inngang», viste seg å ha relativt god effekt på fysisk funksjon, smerte og stemningsleie for voksne med fibromyalgi. Vi lever i en tid hvor de fleste av oss til tider opplever mye stress i hverdagen, men disse pasientene er ekstra utsatt.

Det å lære seg ulike metoder og teknikker for å redusere stress i hverdagen vil være gunstig for alle mennesker, men særlig for dem med kroniske smerter. Disse teknikkene kan åpne for å få mer kontroll over sitt eget liv og velge bort ting i hverdagen som påvirker dem negativt. 
Når det gjelder både helkroppsvibrasjon og TENS, var det for få pasienter og resultater til at det er mulig å gjøre seg opp noen mening om det kan være effektivt for fibromyalgipasienter.

Oversikten som tok for seg kognitive behandlingsformer, viste også gode resultater. Mange pasienter med fibromyalgi sliter med symptomer som angst og depresjon, og for dem spiller kognitiv behandling en stor rolle.

Å være kronisk syk med en så vanskelig og sammensatt sykdom som fibromyalgi er utvilsomt slitsomt, ikke bare for kroppen, men også for psyken. Det kan være lett å havne i en spiral av negative tanker om seg selv, sin egen helse og hverdag.

Kognitiv terapi vil kunne hjelpe pasientene med å endre negative tankem ønstre. Å lære å akseptere sykdommen, leve med den og ta tak i livet sitt for å få en best mulig hverdag er noe av det viktigste man gjør for å kunne takle symptomene og utfordringene som følger med.

\section{Bedre studier om rehabilitering er nødvendig}

Siden mange mennesker er rammet av fibromyalgi, og med tanke på hvor høye samfunnskostnader dette medfører, er det viktig å tilby dem gode rehabiliteringsmuligheter slik at flere kan fungere i arbeid og færre havner i gruppen som blir trygdet.

Det er viktig med opplæring om sykdommen slik at de rammede kan få en bedre livskvalitet og lærer å takle hverdagen og utfordringene de møter. Det er derfor god grunn til å etterlyse flere og bedre studier om tverrfaglig rehabilitering.

Vi kan ikke slå oss til ro med funnene i den aktuelle oversikten. I Norge burde vi kunne lage gode studier om effekten av rehabilitering for fibromyalgipasienter. 
Forskning over en periode på 25 år viser at sykdommer som hjernesvulst, hjerteinfarkt og blodkreft har høy prestisje blant helsepersonell, mens psykiske lidelser og fibromyalgi rangeres lavt (5). Det er ikke urimelig å stille spørsmål ved om sykdommers prestisje påvirker hvordan helsevesenet prioriterer innsatsen, og hvordan forskningsmidler deles ut.

\section{Leger viser ikke alltid forståelse}

Hva gjør det med pasienter å ikke bli trodd? Hvordan er det å ha en sykdom som leger rangerer nederst på rangstigen? Et utvalg på 25 svenske kvinner i alderen 32-65 år med diagnosen fibromyalgi eller kronisk tretthetssyndrom ble intervjuet om dette i en svensk studie (17).

Spørsmålene handlet om disse kvinnenes og andre menneskers syn på sykdommen og kvinnenes strategier for å meste situasjonen. De følte at deres moralske holdning ble trukket i tvil.

Siden sykdommen ikke har noen synlige tegn, opplevde de å ikke bli trodd, og de ble beskyldt for å være arbeidsskye og overdrive plagene sine. De opplevde at leger mente at det var bakenforliggende psykologiske problemer som var årsaken.

\section{三 «Mange skjulte symptomene og levde bak en fasade når de var sammen med andre.»}

Kvinnene fortalte om ulike strategier for å takle sykdommen, blant annet å holde andre på avstand og trekke seg fra et sosialt liv. Mange skjulte symptomene og levde bak en fasade når de var sammen med andre, og kollapset av utmattelse når de kom hjem.

Heldigvis er det også mange norske fagfolk som ser lenger enn til prestisjekåringen. Kirsti Malterud er blant dem som har skrevet om hvordan langvarig stress setter seg i kroppen og blir til kronisk sykdom (18).

Hun skriver: «Å vise pasienten forståelse i praksis er noe annet enn å lete etter årsaker eller funn som en betingelse for å anerkjenne pasientens symptomopplevelse.» 


\section{Konklusjon}

Denne oversikten dokumenterer hva som finnes av forskning om effekten av ikke-medikamentelle behandlingstiltak ved fibromyalgi.

Konklusjonen er at fysisk aktivitet og kognitiv terapi er de mest effektive og best dokumenterte behandlingsformene for fibromyalgipasienter. Det er altså viktig å ta tak i både de fysiske og psykologiske utfordringene ved sykdommen.

Det finnes ikke god nok kunnskap om behandling av fibromyalgi. Det foreligger relativt lite og metodisk svak forskning med tanke på hvor viktig sykdommen er, hvor mange som rammes, og hvor mye den påvirker både pasienter og samfunn. Det kan skyldes at fibromyalgi regnes som en sykdom med lav prestisje blant helsepersonell.

Mer forskning og informasjon om fibromyalgi vil gjøre livet bedre for pasientene, spare samfunnet for store utgifter og gjøre det lettere for fagfolk å forholde seg til denne pasientgruppen.

\section{Referanser}

1. Tollånes MC, Knudsen AK, Vollset SE, Kinge JM, Skirbekk V, Øverland S. Sykdomsbyrden i Norge i 2016. Tidsskr Nor Legeforen. 2018 oktober;(15). DOI: $\underline{10.4045 / \text { tidsskr.18.0274 }}$

2. Forseth $\mathrm{K} \emptyset$. Fibromyalgi - forekomst og risikofaktorer. Tidsskr Nor Legeforen. 2000;120(16):1885. Tilgjengelig fra: https://tidsskriftet.no/2000/06/doktoravhandlinger/fibromyal gi-forekomst-og-risikofaktorer (nedlastet 13.01.2020).

3. $\quad$ Ertesvåg OR. Slik rangerer norske leger sykdommene våre. Oslo: NRK; 2018. Tilgjengelig fra: https://www.nrk.no/norge/slik-rangerer-norske-legersykdommene-vare-1.13867331 (nedlastet 24.04.2019).

4. Folkehelseinstituttet. Helsetilstanden i Norge 2018. Folkehelserapporten - kortversjon. Oslo: Folkehelseinstituttet; 2018. Tilgjengelig fra: http://www.fhi.no/publ/2018/fhr-2018/ (nedlastet 13.01.2020). 
5. Mundal A. Flest til fastlegen på grunn av muskel- og skjelettlidelser. Oslo: Statistisk sentralbyrå; 2018. Tilgjengelig fra: https://www.ssb.no/helse/artikler-og-publikasjoner/flesttil-fastlegen-pa-grunn-av-muskel-og-skjelettlidelser

(nedlastet 02.04.2019).

6. Hørven SH. Fibromyalgi - en oppdatering. Tidsskr Nor Legeforen. 2002;122(13):1300-4. Tilgjengelig fra: https://tidsskriftet.no/2002/05/tema-funksjonellelidelser/fibromyalgi-en-oppdatering (nedlastet 20.10.2019).

7. Hunt H, Pollock A, Campbell C, Estcourt L, Brunton G. An introduction to overviews of reviews: planning a relevant research question and objective for an overview. Systematic Reviews. 2018;(7). DOI: 10.1186/s13643-018-0695-8

8. Busch AJ, Webber SC, Richards RS, Bidonde J, Schachter CL, Schafer LA, et al. Resistance exercise training for fibromyalgia. Cochrane Database of Systematic Reviews. 2013;(12). DOI: 10.1002/14651858.CDo10884

9. Bidonde J, Busch AJ, Webber SC, Schachter CL, Danyliw A, Overend TJ, et al. Aquatic exercise training for fibromyalgia. Cochrane Database of Systematic Reviews. 2014;(10). DOI: $\underline{\text { 10.1002/14651858.CDO11336 }}$

10. Bidonde J, Busch AJ, Schachter CL, Overend TJ, Kim SY, Góes SM, et al. Aerobic exercise training for adults with fibromyalgia. Cochrane Database of Systematic Reviews. 2017; (6). DOI: $10.1002 / 14651858 . C D 012700$

11. Deare JC, Zheng Z, Xue CCL, Liu JP, Shang J, Scott SW, et al. Acupuncture for treating fibromyalgia. Cochrane Database of Systematic Reviews. 2013;(5). Art.nr.: CDoo7070. DOI: 10.1002/14651858.CDo07070.pub2

12. Bernardy K, Klose P, Busch AJ, Choy EHS, Häuser W. Cognitive behavioural therapies for fibromyalgia. Cochrane Database of Systematic Reviews. 2013;(9). DOI: 10.1002/14651858.CDo09796.pub2

13. Bidonde J, Busch AJ, van der Spuy I, Tupper S, Kim SY, Boden C. Whole body vibration exercise training for fibromyalgia. Cochrane Database of Systematic Reviews. 2017; (9). DOI: $\underline{10.1002 / 14651858 . C D 011755 \cdot p u b 2}$ 
14. Johnson MI, Claydon LS, Herbison GP, Jones G, Paley CA. Transcutaneous electrical nerve stimulation (TENS) for fibromyalgia in adults. Cochrane Database of Systematic Reviews. 2017;(10). DOI:

10.1002/14651858.CD012172.pub2

15. Theadom A, Cropley M, Smith HE, Feigin VL, McPherson K. Mind and body therapy for fibromyalgia. Cochrane Database of Systematic Reviews. 2015;(4). DOI: 10.1002/14651858.CDo01980.pub3

16. Karialainen KA, Malmivaara A, Van Tulder MW, Roine R, Jauhiainen M, Hurri H, et al. Multidisciplinary rehabilitation for fibromyalgia and musculoskeletal pain in working age adult. Cochrane Database of Systematic Reviews. 1999;(7). DOI: 10.1002/14651858.CDoo1984

17. Åsbring PI, Närvänen AL. Women's experiences of stigma in relation to chronic fatigue syndrome and fibromyalgia. Qual Health Res. 2002;12(2):148-60. DOI: 10.1177\%2F1049732302012002O2

18. Malterud K. Kroniske muskelsmerter kan forklares på mange måter. Tidsskr Nor Legeforen. 2010;130(23):2356-9.

DOI: $10.4045 /$ tidsskr.09.0828 